\title{
NASA SOIL MOISTURE ACTIVE PASSIVE (SMAP) MISSION FORMULATION ${ }^{1}$
}

\author{
Dara Entekhabi \\ Massachusetts Institute of Technology \\ Cambridge, MA 02139 USA \\ Tel: +1 (617) 253-0698; E-Mail: darae@mit.edu \\ Eni Njoku \\ Jet Propulsion Laboratory \\ California Institute of Technology \\ Pasadena, CA 91109 USA \\ Peggy O’Neill \\ NASA Goddard Spaceflight Center \\ Greenbelt, MD 20771 USA \\ Kent Kellogg \\ Jet Propulsion Laboratory \\ California Institute of Technology \\ Pasadena, CA 91109 USA \\ Jared Entin NASA Headquarters \\ Washington DC 20546 USA
}

\begin{abstract}
The Soil Moisture Active Passive (SMAP) Mission is one of the first Earth observation satellites being formulated by NASA in response to the 2007 National Research Council's Earth Science Decadal Survey [1]. SMAP's measurement objectives are highresolution global measurements of near-surface soil moisture and its freeze-thaw state. These measurements would allow significantly improved estimates of water, energy and carbon transfers between the land and atmosphere. The soil moisture control of these fluxes is a key factor in the performance of atmospheric models used for weather forecasts and climate projections. Soil moisture measurements are also of great importance in assessing flooding and monitoring drought. Knowledge gained from SMAP's planned observations can help mitigate these natural hazards, resulting in
\end{abstract}

\footnotetext{
${ }^{1}$ For planning and discussion purposes only.
} 
potentially great economic and societal benefits. SMAP measurements would also yield high resolution spatial and temporal mapping of the frozen or thawed condition of the surface soil and vegetation. Observations of soil moisture and freeze/thaw timing over the boreal latitudes will contribute to reducing a major uncertainty in quantifying the global carbon balance and help resolve an apparent missing carbon sink over land.

The SMAP mission would utilize an L-band radar and radiometer sharing a rotating 6meter mesh reflector antenna (see Figure 1) [2]. The radar and radiometer instruments would be carried onboard a 3-axis stabilized spacecraft in a $680 \mathrm{~km}$ polar orbit with an 8day repeating ground track. The instruments are planned to provide high-resolution and high-accuracy global maps of soil moisture at $10 \mathrm{~km}$ resolution and freeze/thaw at $3 \mathrm{~km}$ resolution, every two to three days (see Table 1 for a list of science data products). The mission is adopting a number of approaches to identify and mitigate potential terrestrial radio frequency interference (RFI). These approaches are being incorporated into the radiometer and radar flight hardware and ground processing designs.

Four working groups have been established as a means to enable broad science participation in the SMAP mission (Algorithms, Calibration/Validation, Applications, and Radio-Frequency Interference; see http://smap.jpl.nasa.gov/science/wgroups/). The working groups are led by Science Definition Team (SDT) members and provide forums for information exchange on issues related to SMAP science and applications goals and objectives. The working groups communicate via email and at meetings, conference sessions, workshops, and other venues. The SMAP project also includes an international SDT that provides direct links to activities that support SMAP science and applications outside the USA. For example, two airborne field campaigns - one in Canada and another in Australia -- have been conducted in support of testing SMAP algorithms. SMAP has nearly completed its Phase B Mission Concept Study for NASA and it is ready to transition into Phase C. SMAP has a planned target launch date of late 2014. 


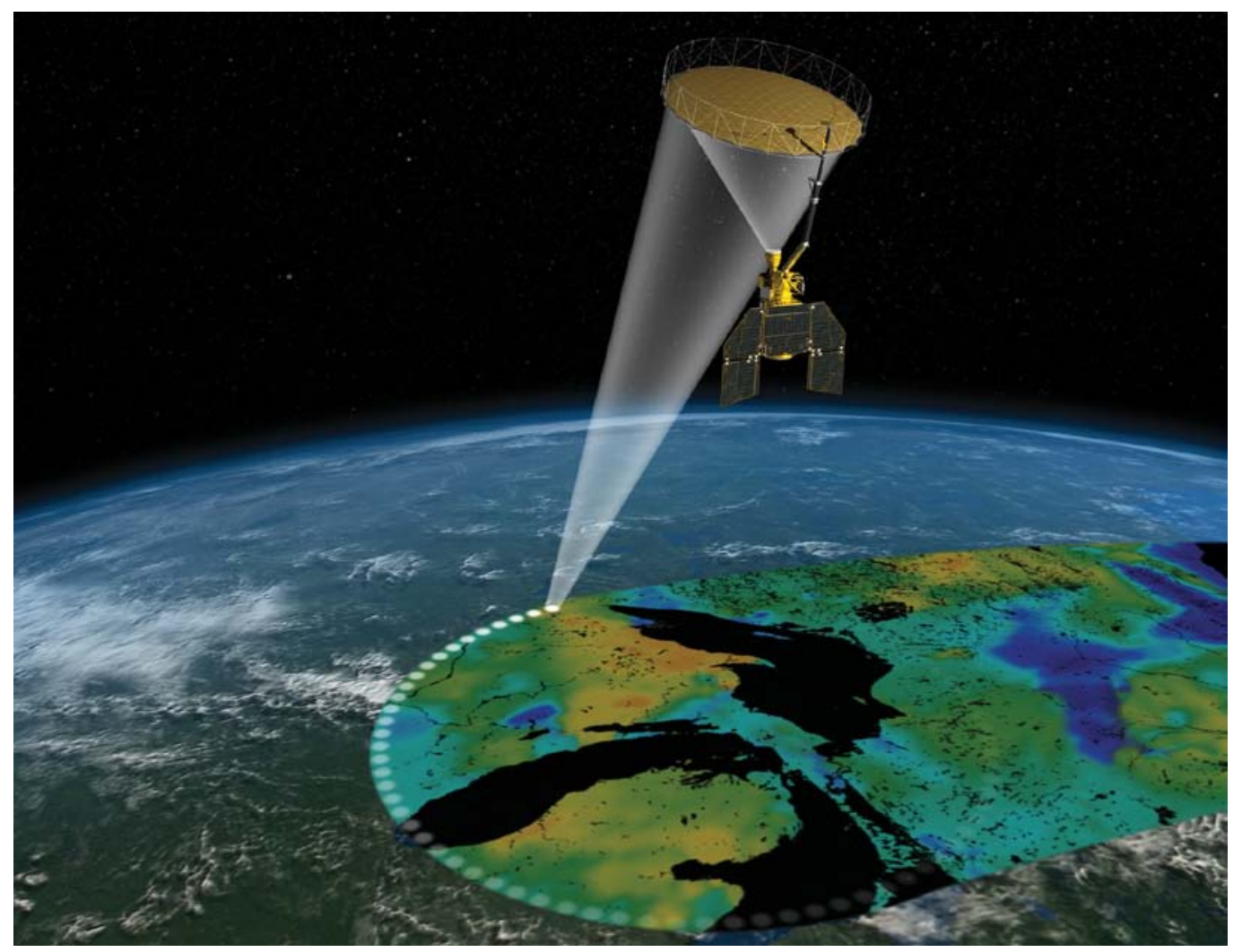

Figure 1: The SMAP Observatory includes a light-weight deployable mesh reflector and the radar and radiometer instruments share a common feed.

\begin{tabular}{|c|c|c|c|c|}
\hline Product & Short Description & Resolution & Latency & \\
\hline L1A_S0 & Radar raw data in time order & - & 12 hours & \multirow{6}{*}{ Instrument Data } \\
\hline L1A_TB & Radiometer raw data in time order & - & 12 hours & \\
\hline L1B_S0_LoRes & Low resolution radar $\sigma_{0}$ in time order & $5 \times 30 \mathrm{~km}$ & 12 hours & \\
\hline L1B_TB & Radiometer $T_{B}$ in time order & $36 \times 47 \mathrm{~km}$ & 12 hours & \\
\hline L1C_S0_HiRes & High resolution radar $\sigma_{o}$ & $1-3 \mathrm{~km}$ & 12 hours & \\
\hline L1C_TB & Radiometer $T_{B}$ & $36 \mathrm{~km}$ & 12 hours & \\
\hline L2_SM_A & Soil moisture (radar) & $3 \mathrm{~km}$ & 24 hours & \multirow{3}{*}{$\begin{array}{l}\text { Science Data } \\
\text { (Half-Orbit) }\end{array}$} \\
\hline L2_SM_P & Soil moisture (radiometer) & $36 \mathrm{~km}$ & 24 hours & \\
\hline L2_SM_A/P & Soil moisture (radar/radiometer) & $9 \mathrm{~km}$ & 24 hours & \\
\hline L3_SM_A & Soil moisture (radar) & $3 \mathrm{~km}$ & 24 hours & \multirow{4}{*}{$\begin{array}{c}\text { Science Data } \\
\text { (Daily Composite) }\end{array}$} \\
\hline L3_F/T_A & Freeze/thaw state (radar) & $3 \mathrm{~km}$ & 50 hours & \\
\hline L3_SM_P & Soil moisture (radiometer) & $36 \mathrm{~km}$ & 50 hours & \\
\hline L3_SM_A/P & Soil moisture (radar/radiometer) & $9 \mathrm{~km}$ & 50 hours & \\
\hline L4_SM & Soil moisture (surface \& root zone) & $9 \mathrm{~km}$ & 7 days & \multirow{2}{*}{$\begin{array}{c}\text { Science } \\
\text { Value-Added }\end{array}$} \\
\hline L4_C & Carbon net ecosystem exchange (NEE) & $9 \mathrm{~km}$ & 14 days & \\
\hline
\end{tabular}

Table 1: The suite of SMAP science data products with associated spatial resolution and availability-latency from the time of acquisition. 


\section{REFERENCES}

[1] National Research Council, "Earth Science and Applications from Space: National Imperatives for the Next Decade and Beyond,” 2007.

[2] Entekhabi, D., E, Njoku, P. O’Neill, K. Kellogg, et al., "The Soil Moisture Active Passive (SMAP) Mission,” Proceedings of the IEEE, Vol. 98, No. 5, May, 2010. 